\title{
High-resolution glacial and deglacial record of atmospheric methane by continuous-flow and laser spectrometer analysis along the NEEM ice core
}

\author{
J. Chappellaz ${ }^{1,{ }^{* *}}$, C. Stowasser ${ }^{2,{ }^{* *}}$, T. Blunier ${ }^{2}$, D. Baslev-Clausen ${ }^{2}$, E. J. Brook ${ }^{3}$, R. Dallmayr ${ }^{1, *}$, X. Faïn ${ }^{1}$, J. E. Lee ${ }^{3}$, \\ L. E. Mitchell ${ }^{3}$, O. Pascual ${ }^{1}$, D. Romanini ${ }^{4}$, J. Rosen $^{3}$, and S. Schüpbach ${ }^{5}$ \\ ${ }^{1}$ UJF - Grenoble 1/CNRS, UMR5183, CNRS - Laboratoire de Glaciologie et Géophysique de l'Environnement (LGGE), \\ Grenoble, France \\ ${ }^{2}$ Centre for Ice and Climate, Niels Bohr Institute, University of Copenhagen, Copenhagen, Denmark \\ ${ }^{3}$ College of Earth, Ocean and Atmospheric Sciences, Oregon State University, Corvallis, OR, USA \\ ${ }^{4}$ UJF - Grenoble 1/CNRS, LIPhy UMR5588, Grenoble, France \\ ${ }^{5}$ Physics Institute, Climate and Environmental Physics and Oeschger Centre for Climate Change Research, \\ University of Bern, Bern, Switzerland \\ *now at: National Institute of Polar Research, Tokyo, Japan \\ ** These authors contributed equally to this work.
}

Correspondence to: J. Chappellaz (chappellaz@lgge.obs.ujf-grenoble.fr)

Received: 26 April 2013 - Published in Clim. Past Discuss.: 13 May 2013

Revised: 16 September 2013 - Accepted: 25 September 2013 - Published: 14 November 2013

\begin{abstract}
The Greenland NEEM (North Greenland Eemian Ice Drilling) operation in 2010 provided the first opportunity to combine trace-gas measurements by laser spectroscopic instruments and continuous-flow analysis along a freshly drilled ice core in a field-based setting. We present the resulting atmospheric methane $\left(\mathrm{CH}_{4}\right)$ record covering the time period from 107.7 to $9.5 \mathrm{ka}$ b2k (thousand years before $2000 \mathrm{AD}$ ). Companion discrete $\mathrm{CH}_{4}$ measurements are required to transfer the laser spectroscopic data from a relative to an absolute scale. However, even on a relative scale, the high-resolution $\mathrm{CH}_{4}$ data set significantly improves our knowledge of past atmospheric methane concentration changes. New significant sub-millennial-scale features appear during interstadials and stadials, generally associated with similar changes in water isotopic ratios of the ice, a proxy for local temperature. In addition to the midpoint of Dansgaard-Oeschger (D/O) $\mathrm{CH}_{4}$ transitions usually used for cross-dating, sharp definition of the start and end of these events brings precise depth markers (with $\pm 20 \mathrm{~cm}$ uncertainty) for further cross-dating with other palaeo- or ice core records, e.g. speleothems. The method also provides an estimate of $\mathrm{CH}_{4}$ rates of change. The onsets of D/O events
\end{abstract}

in the methane signal show a more rapid rate of change than their endings. The rate of $\mathrm{CH}_{4}$ increase associated with the onsets of $\mathrm{D} / \mathrm{O}$ events progressively declines from 1.7 to $0.6 \mathrm{ppbv} \mathrm{yr}^{-1}$ in the course of marine isotope stage 3 . The largest observed rate of increase takes place at the onset of $\mathrm{D} / \mathrm{O}$ event \#21 and reaches $2.5 \mathrm{ppbv} \mathrm{yr}^{-1}$.

\section{Introduction}

The methane $\left(\mathrm{CH}_{4}\right)$ mixing ratio in air bubbles is one of the components which has been systematically measured along ice cores since the late 1980s. Large changes of this greenhouse gas on glacial-interglacial (Loulergue et al., 2008) and millennial (e.g. Chappellaz et al., 1993; Brook et al., 1996) timescales have been revealed. In addition, atmospheric methane is one of the few variables which have global significance and is reliably recorded in ice cores from Antarctica and Greenland. This feature has been used to provide a common time frame in the gas phase between ice cores and to discuss the well-known see-saw feature of hemispheric temperature changes during Dansgaard-Oeschger $(\mathrm{D} / \mathrm{O})$ events

Published by Copernicus Publications on behalf of the European Geosciences Union. 
and the last deglaciation (e.g. Blunier et al., 1998; Blunier and Brook, 2001; EPICA community members, 2006).

For more than two decades, the $\mathrm{CH}_{4}$ mixing ratio in ice cores have been measured on discrete samples of typically $40-50 \mathrm{~g}$ systematically selected along the core. The usual analytical method combines a melting (wet) or crushing/grating (dry) extraction of the trapped gases under vacuum followed by gas chromatographic analysis of $\mathrm{CH}_{4}$ (e.g. Nakazawa et al., 1993; Sowers et al., 1997; Etheridge et al., 1998; Flückiger et al., 2004; Mitchell et al., 2011). The method provides a typical absolute uncertainty in the range of $3-15 \mathrm{ppbv}$ (relative standard error of 0.5 to $4 \%$ ), but it is time consuming even though now partly automated and performed on several samples at once. The first attempt to measure $\mathrm{CH}_{4}$ along a core using continuous-flow analysis (CFA) and continuous gas separation was conducted by the University of Bern (Schüpbach et al., 2009). The extracted gas was continuously collected in $15 \mathrm{~cm}$ step increments along the core and then injected into a gas chromatograph (GC), with a typical reproducibility in the range of 10-20 ppbv. More recently, Stowasser et al. (2012) developed a modified CFA gas extraction setup and substituted the GC with a commercially available laser spectrometer using wavelength-scanned cavity ring-down spectroscopy (WS-CRDS). It provides much better precision and spatial resolution of the measurements $(0.8 \mathrm{ppbv}$ and $5 \mathrm{~cm}$, respectively), and it is non-destructive. Therefore several laser spectrometers can be installed in series for replicates or for investigating other trace gases. The method has been successfully applied in the laboratory on a $400 \mathrm{~m}$ long core drilled during the 2011 field campaign of the North Greenland Eemian Ice Drilling (NEEM: $77.45^{\circ} \mathrm{N}$, $51.06^{\circ} \mathrm{W}$ ). It provided a detailed $\mathrm{CH}_{4}$ record covering the last $2000 \mathrm{yr}$ (Rhodes et al., 2013) as well as a CO profile (Faïn et al., 2013).

Here we present and discuss the methane results obtained during the spring-summer 2010 field campaign at NEEM, using a similar analytical setup as described in Stowasser et al. (2012). In 53 days, $868 \mathrm{~m}$ of freshly drilled ice cores was processed. Three instruments for measurements of methane mixing ratios were installed in series downstream of the CFA gas extraction system: a prototype laser spectrometer using optical-feedback cavity-enhanced absorption spectroscopy (OF-CEAS; SARA instrument, LIPhy, Grenoble, France), a WS-CRDS (Picarro Inc., CFADS36 analyser) and a GC. The CFA $\mathrm{CH}_{4}$ time series were obtained in a timeefficient manner without dedicated ice sampling (it uses the portion of the ice core which has already been dedicated to CFA chemistry analysis), and are of high spatial resolution. Those obtained with the laser spectrometers are of high precision (not accuracy). Thus, they bring further constraints on the timing of $\mathrm{CH}_{4}$ changes, the speed of transitions and on sub-millennial-scale variability, as discussed below. For clarity, we will use the INTIMATE nomenclature (Rousseau et al., 2006) to name the $\mathrm{CH}_{4}$ events, considering them in phase at first order with the Greenland temperature changes associ-

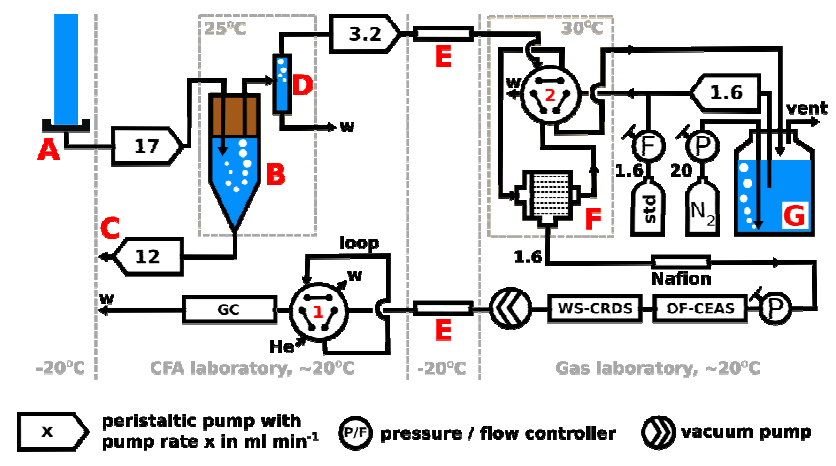

Fig. 1. The experimental setup for continuous measurements of $\mathrm{CH}_{4}$ mixing ratio as deployed during the NEEM 2010 field season. Ice core rods are melted on a heated melt head (A). Gas is extracted from the melt water in three stages: first in a debubbler (B), followed by an open split (D) and finally in a gas extraction module $(F)$. The melt water is used for chemical analyses (C and D). A heated transfer line (E) connects the two laboratories. Degassed, deionized water $(G)$ is mixed with standard gas (std) to replace the sample stream between measurements. Numbers without units denote water or gas flow rates in $\mathrm{mL}$ min, and waste is abbreviated as w.

ated with $\mathrm{D} / \mathrm{O}$ events. Therefore the maxima are named GIS for Greenland interstadials, and the minima GS for Greenland stadials. The same numbering is applied to a GIS and its preceding GS.

\section{Experimental procedure}

The experimental setup for continuous measurements of $\mathrm{CH}_{4}$ mixing ratios as deployed during the NEEM 2010 field season is shown in Fig. 1 . The $2.6 \mathrm{~cm} \times 2.6 \mathrm{~cm}$ inner section of ice core rods of $1.1 \mathrm{~m}$ length (along the long axis of the core) used for gas and chemistry analyses is melted on a heated melt head (A in Fig. 1) at an average rate of $3.2 \mathrm{~cm} \mathrm{~min}^{-1}$ in a cold environment $\left(T \approx-20^{\circ} \mathrm{C}\right)$.

In the warm laboratory for CFA chemical measurements $\left(T \approx 20^{\circ} \mathrm{C}\right)$ a peristaltic pump passes the stream of melt water and bubbles of past atmospheric air $\left(17 \mathrm{~mL} \mathrm{~min}^{-1}\right.$, ca. $10 \%$ air by volume) to a sealed debubbler (B in Fig. 1). The debubbler (internal volume of ca. $0.8 \mathrm{~mL}$ ) distributes the sample between several systems for chemical analyses and the system for the analysis of $\mathrm{CH}_{4}$ mixing ratios (for details see Kaufmann et al., 2008; Schüpbach et al., 2009; Stowasser et al., 2012).

A second peristaltic pump removes $12 \mathrm{~mL} \mathrm{~min}^{-1}$ of bubble-free water from the bottom of the debubbler for chemical analyses ( $\mathrm{C}$ in Fig. 1). The difference in flow between input $\left(17 \mathrm{~mL} \mathrm{~min}^{-1}\right)$ and output $\left(12 \mathrm{~mL} \mathrm{~min}^{-1}\right)$ leaves the top of the debubbler towards an open split (D in Fig. 1). The open split prevents pressure fluctuations in the debubbler that would disturb the chemical analyses. A third peristaltic pump (with LFL tubing, Ismatec) removes all the air 
bubbles and some residual water $\left(3.2 \mathrm{~mL} \mathrm{~min}^{-1}\right.$, ca. $50 \%$ air by volume) at the top of the open split. The sample is pushed through a heated transfer line $\left(T \approx 20^{\circ} \mathrm{C}\right.$, E in Fig. 1) towards a second warm laboratory $\left(T \approx 20^{\circ} \mathrm{C}\right)$ including the $\mathrm{CH}_{4}$ analysis system.

There, the sample gas is continuously extracted from the residual water through a module containing a gas permeable membrane (F in Fig. 1, MicroModule 0.5" $\times 1^{\prime \prime}$, G591, Membrana $\mathrm{GmbH}$, Germany, internal volume $5.4 \mathrm{~mL}$ ) installed in a temperature-regulated box $\left(T \approx 30^{\circ} \mathrm{C}\right)$. A builtin vacuum pump of the WS-CRDS instrument maintains a pressure gradient between the WS-CRDS cavity ( $62 \mathrm{mbar}$ ), the OF-CEAS cavity (70 mbar) and the gas outlet of the hydrophobic, gas-permeable membrane in the module (364 to $450 \mathrm{mbar})$. The resulting pressure drop of $\sim 300-400 \mathrm{mbar}$ across the membrane was sufficient to extract non-dissolved air from the sample stream. A compact micro-fluidic pressure controller (Bronkhorst, IQ + FLOW, the Netherlands) at the inlet of the OF-CEAS instrument controls the upstream pressure (set in the range 364-450 mbar during the field campaign) at the outlet of the gas extraction module in order to stabilize the gas permeation conditions through the membrane.

The extracted sample gas flowing on average at $1.6 \mathrm{~mL} \mathrm{~min}^{-1}$ is dried through a $2 \mathrm{~m}$ long custom-made Nafion dryer (Nafion TT-020, Perma Pure LLC, $0.3 \mathrm{~mm}$ inner diameter). With a purge flow of ca. $20 \mathrm{~mL} \mathrm{~min}^{-1}$ (dry nitrogen, technical grade, Air Liquide) the remaining water vapour mixing ratio is ca. $0.03 \%$ by volume or lower as measured by the WS-CRDS and OF-CEAS instruments.

The dried sample is directed through two optical analysers for continuous measurements of $\mathrm{CH}_{4}$ and $\mathrm{H}_{2} \mathrm{O}$ mixing ratios (OF-CEAS and WS-CRDS, connected in series). The OF-CEAS instrument also quantified $\mathrm{N}_{2} \mathrm{O}$ (down to the ppbv level, not discussed here). For details about the measurement procedure of the two instruments we refer the reader to Sect. 3 (OF-CEAS) and work by Crosson (2008) and Stowasser et al. (2012) (WS-CRDS).

Both measurement techniques are non-destructive, and the WS-CRDS pump does not contaminate for methane. This allows for sending the sample back to the CFA warm laboratory through the heated transfer line (E in Fig. 1). Here, $\mathrm{CH}_{4}$ mixing ratios are measured again by a $\mathrm{GC}$ as described in Schüpbach et al. (2009). Upstream of the GC, an automated six-port valve is installed (\#1 in Fig. 1; Valco C6W, VICI AG, Switzerland) that switches when the GC is ready for measurements: a helium carrier stream $\left(4 \mathrm{~mL} \mathrm{~min}^{-1}\right)$ flushes the sample out of a loop (internal volume $0.45 \mathrm{~mL}$ ) and into the GC column, where $\mathrm{CH}_{4}$ is separated from all other components. $\mathrm{CH}_{4}$ mixing ratios are determined by detecting the amount of $\mathrm{CH}_{4}$ in the sample with a pulsed discharge detector (PDD) and correcting the results for the total sample by simultaneous detection of the amount of krypton $(\mathrm{Kr})$ in the sample with the PDD (see Schüpbach et al., 2009 for details).
When a new ice rod is placed on the melt head or during system maintenance, the CFA system idles and ambient air can enter the gas analysis system through the melt head. To prevent the gas extraction module being filled with ambient air, a water-gas mixture $\left(3.2 \mathrm{~mL} \mathrm{~min}^{-1}\right.$, ca. $50 \%$ air by volume) of deionized water and bottled gas (SARA1 and SARA2 standards, composition of $21 \% \mathrm{O}_{2}$ and $79 \% \mathrm{~N}_{2}$, with 704.4 and $672.7 \mathrm{ppbv}$ of $\mathrm{CH}_{4}$, respectively) is injected into the gas extraction module via an automated six-port valve (\#2 in Fig. 1, Cheminert C22Z-3186EH, VICI AG). The deionized water ( $\mathrm{G}$ in Fig. 1) is degassed with a stream of nitrogen gas (ca. $20 \mathrm{~mL} \mathrm{~min}^{-1}$, dry nitrogen, technical grade, Air Liquide) to keep the composition of the dissolved gas roughly constant. A peristaltic pump (Ismatec REGLO Digital MS-4/12, ISM 597, IDEX Health \& Science SA, Switzerland) and a mass flow controller (MFC 5850E, Brooks Instrument, USA) control the water and gas flow rate, respectively. In the following, we refer to this part of the system as the "loop mode".

A similar experimental setup was deployed during the NEEM 2011 field season and is described in Stowasser et al. (2012). The 2011 setup differs in the following aspects:

- $\mathrm{CH}_{4}$ mixing ratios are measured only with the WS-CRDS.

- The reservoir for deionized water ( $G$ in Fig. 1) is located in the temperature-controlled box $\left(T=30.0 \pm 0.2^{\circ} \mathrm{C}\right)$.

- A second gas-water mixture of deionized water and standard gas is injected below the melt head ( $\mathrm{A}$ in Fig. 1) to calibrate the complete CFA and gas extraction system.

\section{OF-CEAS (SARA) instrument}

The NEEM 2010 field season allowed for the first polar field deployment of a prototype OF-CEAS laser spectrometer called SARA (LIPhy, Grenoble, France). It differs from WS-CRDS as the measurement relies on quantifying the light transmission of a high-finesse optical cavity at a sequence of precisely given wavelengths instead of measuring a ringdown time (see Romanini et al., 2006, for technical details). Thanks to optical feedback locking the laser frequency to the cavity resonances, the frequency of acquisition of the absorption spectrum by the sample present inside the cavity is larger than in the WS-CRDS instrument: $5 \mathrm{~Hz}$ for the NEEM campaign. The absorption spectrum is measured in the wavelength range $2275.3-2275.6 \mathrm{~nm}$, where $\mathrm{CH}_{4}$ and $\mathrm{N}_{2} \mathrm{O}$ strong absorption lines occur at 2275.4457 and $2275.5122 \mathrm{~nm}$, respectively. Spectra are averaged by the instrument, typically over $1 \mathrm{~s}$. On a few occasions, this was inadvertently increased by the field operator to $10 \mathrm{~s}$, affecting the standard error as discussed in Sect. 8. The inner walls of the OF-CEAS sample 
cavity were passivated with a Silcosteel (Restek, USA) treatment, and the internal volume $\left(12 \mathrm{~cm}^{3}\right)$ is smaller compared to the WS-CRDS $\left(33 \mathrm{~cm}^{3}\right)$. Although lower cavity pressure could have been achieved without compromising the instrument performance, it was set at 70 mbar during the 2010 NEEM field season to provide a significant pressure gradient with the WS-CRDS downstream (62 mbar cavity pressure).

In theory, $0.8 \mathrm{~cm}^{3}$ of sample gas at standard temperature and pressure is required to fill the cavity, which translates to a sample residence time of $30 \mathrm{~s}$ (equivalent to $1.5 \mathrm{~cm}$ of ice sample run on the CFA melt head) at a typical CFA gas flow rate of $1.6 \mathrm{~mL} \mathrm{~min}^{-1}$. In reality, other sources of smoothing along the experimental setup due to sample dispersion and/or memory effects degrade the system resolution, as discussed below. Due to its better theoretical resolution, the OF-CEAS instrument was installed upstream from the WS-CRDS instrument.

The temporal resolution of the OF-CEAS instrument in combination with the experimental setup was evaluated using a step test between standard gas and sample mode, which defines the transfer function of the experimental setup (Gkinis et al., 2010; Stowasser et al., 2012). It shows that the instrument can resolve a periodic input signal with frequencies below $0.01 \mathrm{~s}^{-1}$. Given the melt rate of $3.2 \mathrm{~cm} \mathrm{~min}^{-1}$, a periodic $\mathrm{CH}_{4}$ signal with a wavelength of $5.3 \mathrm{~cm}$ can still be detected, although its amplitude will be significantly dampened.

\section{Changes in the experimental setup during the field season}

The experimental setup for continuous measurements of $\mathrm{CH}_{4}$ mixing ratios (Sect. 2) was subject to changes during the course of the NEEM 2010 field season (eight weeks of measurements along $868 \mathrm{~m}$ of ice). Table 1 provides a list of the changes, which (potentially) had an influence on the measurements. The changes are ordered according to the depth of the measured ice.

We noticed that the gas extraction efficiency of the MicroModule degrades constantly with time, presumably since dust particles from the sample stream accumulate in the unit. Hence, a new module was installed whenever the gas extraction started to become incomplete (bubbles visible downstream of the MicroModule). At a depth of $1647.25 \mathrm{~m}$ the direction of the MicroModule was changed so that the buffer volume of the unit was located at the inlet (as shown in Fig. 1). This led to significant reduction in the measurement noise, probably related to reduced pressure changes outside the membrane.

Particles can also lead to a (partial) clogging of a valve or a piece of tubing. The replacement of tubing or the cleaning of valves/tubing is noted down as "gas extraction maintenance" in Table 1. Furthermore, we detected and reduced leaks at the outlet of the OF-CEAS and at the MicroModule, and once changed the pressure upstream of the OF-CEAS.
Table 1. Changes in the experimental setup, which (potentially) had an influence on the continuous measurements of $\mathrm{CH}_{4}$ mixing ratios during the NEEM 2010 field season.

\begin{tabular}{cl}
\hline Depth [m from top] & Change \\
\hline 1332.65 & Start of gas measurements \\
1352.45 & Leak at OF-CEAS outlet reduced \\
1359.05 & Leak at OF-CEAS outlet reduced \\
1397.55 & Gas extraction maintenance \\
1493.25 & OF-CEAS maintenance \\
1518.55 & OF-CEAS online \\
1529.55 & Gas extraction maintenance \\
1551.55 & Gas extraction maintenance \\
1612.05 & New MicroModule \\
1631.85 & Pressure upstream OF-CEAS: \\
& 364 to 450 mbar \\
1647.25 & Gas extraction maintenance, \\
& direction MicroModule changed \\
& (buffer volume upstream) \\
1808.95 & New MicroModule, \\
& Gas extraction maintenance \\
1817.75 & Leak at MicroModule reduced \\
1949.75 & New MicroModule \\
2031.15 & Change in debubbler (tube position) \\
2033.35 & Change in debubbler (tube position) \\
2057.55 & Nafion N2 purge off - wet sample \\
2074.05 & Nafion maintenance - wet sample \\
2126.85 & New MicroModule \\
2137.85 & Nafion online \\
2200.55 & End of gas measurements \\
\hline &
\end{tabular}

Due to maintenance of the OF-CEAS, only the WS-CRDS and the GC measured the sample gas between 1493.25 and $1518.55 \mathrm{~m}$ depth.

Between 2031.15 and $2033.35 \mathrm{~m}$ depth, the position of the inlet and outlet tubing in the debubbler was altered. Towards the end of the field season at a depth of $2057.55 \mathrm{~m}$, the $\mathrm{N}_{2}$ purge of the Nafion dryer failed and the water vapour content of the measured sample considerably increased. After maintenance the Nafion dryer was operational again at a depth of $2137.85 \mathrm{~m}$.

In Fig. 5, $\mathrm{CH}_{4}$ measurements of the NEEM 2010 field season are plotted on a depth scale, and the occurrence of changes in the experimental setup are marked as dashed vertical lines. Intervals between two adjacent changes are treated alike during calibration as described in Sect. 8. 


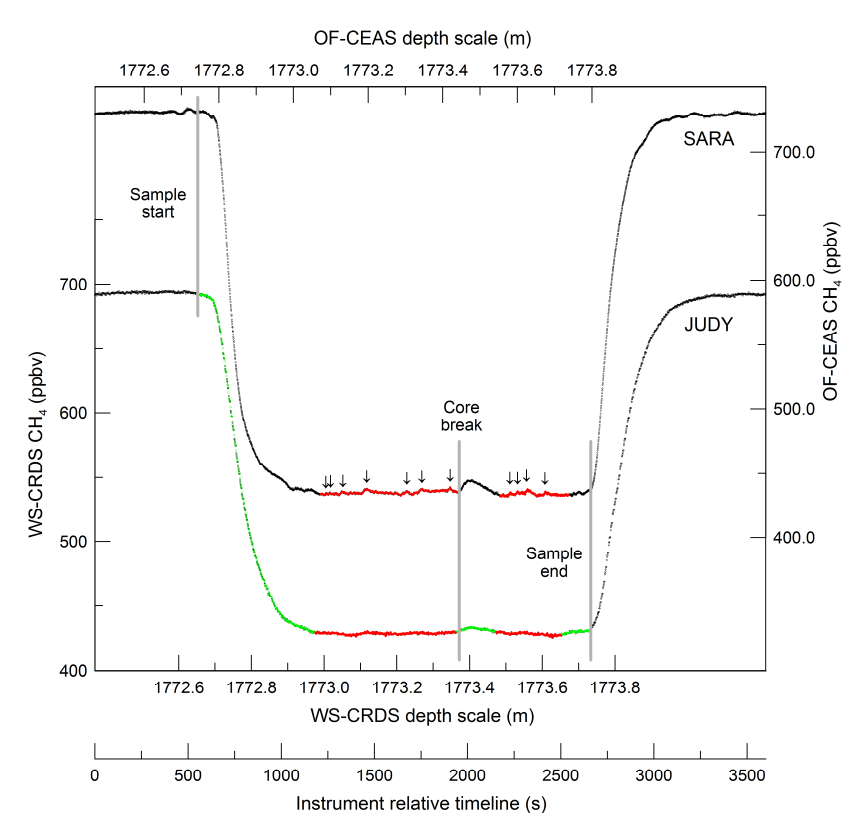

Fig. 2. Example of a sample run, in this case bag \#3224-3225 covering the depth range from 1772.65 to $1773.75 \mathrm{~m}$, after synchronization of the two instrument relative timelines. The sequence shown here has a duration of about one hour, with $\sim 25$ min of sample-only measurement. OF-CEAS (WS-CRDS) data points (black dots) are equally spaced every $1 \mathrm{~s}(1.7 \mathrm{~s})$. The green sequence corresponds to the full sample run according to the WS-CRDS procedure. The two red sequences are retained sample values for both instruments. In this example, a core break is located at $1773.38 \mathrm{~m}$ depth, contaminating the gas sample for about $3 \mathrm{~min}$. The corresponding sequence is thus rejected. Arrows along the OF-CEAS sequence point out a small $\mathrm{CH}_{4}$ variability (here $1-3 \mathrm{ppbv}$ ) at the scale of a few tens of seconds, probably generated by changing gas permeation conditions through the MicroModule.

\section{Data selection and translation to a depth scale}

The laser spectrometer data are recorded as a function of time, and require post-data-acquisition treatment to be put on a depth scale (Stowasser et al., 2012; Rhodes et al., 2013). As illustrated in Fig. 2, each $110 \mathrm{~cm}$ long sample run is framed by continuous standard gas analysis using the loop mode. Ice cores were melted from top to bottom; that is, the end of a sample measurement in the time domain corresponds to the bottom depth of the melted ice core in the depth domain (in the example of Fig. 2, it is $1773.746 \mathrm{~m}$ ).

It takes time to renew the gas within the experimental setup and cavity volumes until the laser spectrometers only detect sample gas. Therefore a significant part of the start of each sample is lost due to mixing with remaining standard gas from the loop mode. At the end of each run, the automated six-port valve (\#2 in Fig. 1) was switched to loop mode only a few seconds before the transfer line would run out of sample gas, so in essence the sample was measured until its very end. This feature could be visually followed through the transparent plastic tubing leading to the MicroModule thanks to the different water-gas partitioning along the tubing between sample and loop mode. On a few occasions, the automated valve would not switch to loop mode (missed electronic trigger from the CFA lab), thus bringing ambient air above the melt head into the gas line, with $\mathrm{CH}_{4}$ mixing ratio above 2000 ppbv. This indeed provided an even clearer "end of sample" location as a function of time. Forced ambient air intrusion at the end of a run has become part of the CFA gas measurement procedure in more recent measurement campaigns (Stowasser et al., 2012; Rhodes et al., 2013), including the 2011 NEEM CFA field season.

Two different procedures were used to transfer the laser spectrometer time series to a depth scale and to define the data section to be removed due to mixing with gas from the loop mode, as explained in Sect. 5.1 (OF-CEAS) and Sect. 5.2 (WS-CRDS). Furthermore, instrumental problems or $\mathrm{CH}_{4}$ contamination due to core breaks required additional data selection. The comparison of two parallel $\mathrm{CH}_{4}$ series with the WS-CRDS and the OF-CEAS instruments proved to be very useful to confirm or disallow the rejection of specific data points.

\subsection{Depth scale for the OF-CEAS data}

As can be seen in Fig. 2, the slope changes at the start and end of a run are more pronounced in the OF-CEAS instrument than in the WS-CRDS one. This is due to the smaller effective volume of the sample cavity of the OF-CEAS combined with the OF-CEAS that is the first instrument in the series. However this also leads to resolving more variability (wavelength of a few tens of seconds or more) in the gas composition from the transfer lines, both in sample mode and in loop mode (Fig. 2). Such variability cannot reflect changes in the gas composition in the ice, as its wavelength is shorter than the resolution of a periodic input by the OFCEAS (Sect. 3). We suspect that it reflects changing permeation conditions through the MicroModule due to variable water-gas partitioning in the MicroModule volume. The data selection procedure for the OF-CEAS time series was done manually based on the general shape of each $\mathrm{CH}_{4}$ run. The changes in gas flow rate through the OF-CEAS (continuously measured downstream from the cavity) were used as an independent criterion in ambiguous cases. As illustrated in Fig. 2, the end of an OF-CEAS sample run was usually characterized by a small oscillation preceding the increasing slope toward loop mode mixing ratios and which was thus rejected. The beginning of undisturbed (and thus selected: red line in Fig. 2) measurements was defined where no more trend could be seen in the $\mathrm{CH}_{4}$ signal. When the run included an atmospheric signal slope associated with, for example, the start of a D/O event, data selection started at the first observed slope change in the downward OF-CEAS $\mathrm{CH}_{4}$ trend. The manual selection procedure was always conservative in ambiguous cases. 
The length of the melted ice core $(\mathrm{cm})$ and the average melt rate $\left(\mathrm{cm} \mathrm{min}^{-1}\right)$ are routinely and continuously measured in the CFA system. They can be used to calculate the time it takes to melt a core (melt time). For the OF-CEAS data series, we assign the bottom depth of the sample to the end of the data selection (in the example of Fig. 2: vertical grey line at $1773.746 \mathrm{~m}$ ). Then, the depth domain is completed upward by multiplying the time domain by the average melt rate of the run (thus assuming no significant variation during the course of a run).

\subsection{Depth scale with the WS-CRDS data}

As shown in the lower curve in Fig. 2, $\mathrm{CH}_{4}$ measurements along the entire ice core sample (green circles) are extracted from the continuous record by manually defining the end of the sample measurement (vertical grey line), which is characterized by a steep increase in the $\mathrm{CH}_{4}$ mixing ratio (from the value of the sample to the value of the standard gas).

Subsequently, the start of a sample measurement is determined by subtracting the known CFA melt time from the end of the measurement in the time domain. The start of a measurement in the time domain corresponds to the top depth of the melted ice core in the depth domain (in the example of Fig. 2: vertical grey line at $1772.650 \mathrm{~m}$ ). The depth domain is completed by linearly interpolating between the top and the bottom depth using the average melt rate of the run. Whenever a section of the core had to be removed prior to melting (e.g. due to cracks and the potential for contamination), the associated shift in the depth scale was taken into account. For the example shown in Fig. 2, a section of $0.7 \mathrm{~cm}$ had to be removed at a depth of $1773.357 \mathrm{~m}$, resulting in a core break (vertical grey line).

The first part of the measurement is removed since it takes about $10 \mathrm{~min}$ to sweep the standard gas out of the analytical system and the instruments. The exact time depends on many system parameters, such as the melt speed, the difference in $\mathrm{CH}_{4}$ mixing ratio between standard gas and sample, or varying signal smoothing in the system (e.g. degrading gas extraction efficiency). Often it is difficult to choose the point at which the sample measurement is supposedly uncontaminated (1772.973 $\mathrm{m}$ for the WS-CRDS in Fig. 2), especially in cases where the $\mathrm{CH}_{4}$ mixing ratio in the sample is decreasing.

For the WS-CRDS, we estimated the time at which the standard gas contamination would be below the detection level of the optical instrument by performing step function analyses. A step analysis example is shown in Fig. 3, where the beginning of an ice core measurement (blue) and the corresponding fit (red) are plotted versus measurement time. For fitting we use the cumulative distribution function of a lognormal distribution (for details see e.g. Gkinis et al., 2010). The time scale is shifted so that the minimum derivative corresponds to $t=0 \mathrm{~s}$. In this example the fit drops below the 5

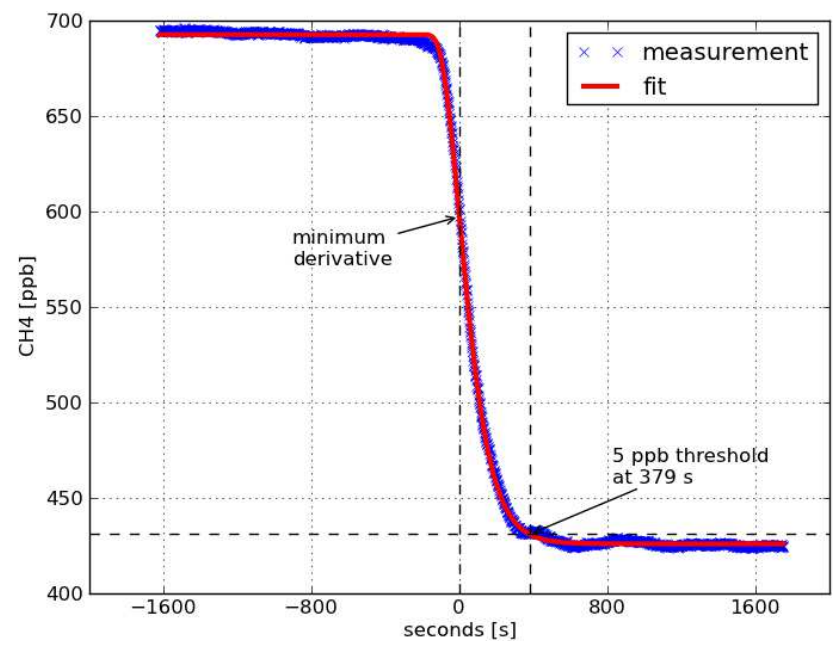

Fig. 3. Example of a step analysis for the WS-CRDS data to determine the beginning of ice core measurements, unaffected by mixing with standard gas from the loop mode.

ppbv threshold at a sweeping time of 379 s (with respect to the baseline of $426 \mathrm{ppbv}$ ).

The threshold of $5 \mathrm{ppbv}$ was chosen since measurements of $\mathrm{CH}_{4}$ mixing ratios from ice core samples show fluctuations of the order of 5-10 ppbv in the WS-CRDS data series as a consequence of varying system conditions (e.g. pressure instabilities at the MicroModule or variations in the sample flow rate). Therefore, $5 \mathrm{ppbv}$ is a more reasonable choice for the threshold compared to, for example, the measurement precision, which is of the order of 1 ppbv or smaller as characterized by Stowasser et al. (2012).

A stable $\mathrm{CH}_{4}$ measurement along the ice core sample is needed for the step analysis to yield good estimates of the sweeping time. However, $\mathrm{CH}_{4}$ mixing ratios often increase or decrease during the measurements along an ice core sample, and hence the step analysis cannot be performed for each sample. Instead, we perform three step analyses per measurement day and determine the average value of the three sweeping time estimates. If less than three stable steps are available, then the average sweeping time is determined from only $1-2$ step analyses.

The average sweeping time enables us to objectively estimate at what time the standard gas contamination would be below the detection level of the WS-CRDS instrument. Occasionally, manual adjustments to the sweeping time are needed since the average sweeping time is based on three measurements maximum per day only, and system conditions can vary between individual ice core measurements.

In the example of Fig. 2, the very last part of the sample measurement had to be removed due to fluctuations in the cavity pressure of the WS-CRDS (not shown). The red dots in Fig. 2 indicate the parts of the measurement that are assumed to be undisturbed and are used to compile the $\mathrm{CH}_{4}$ data set as measured by the WS-CRDS. 


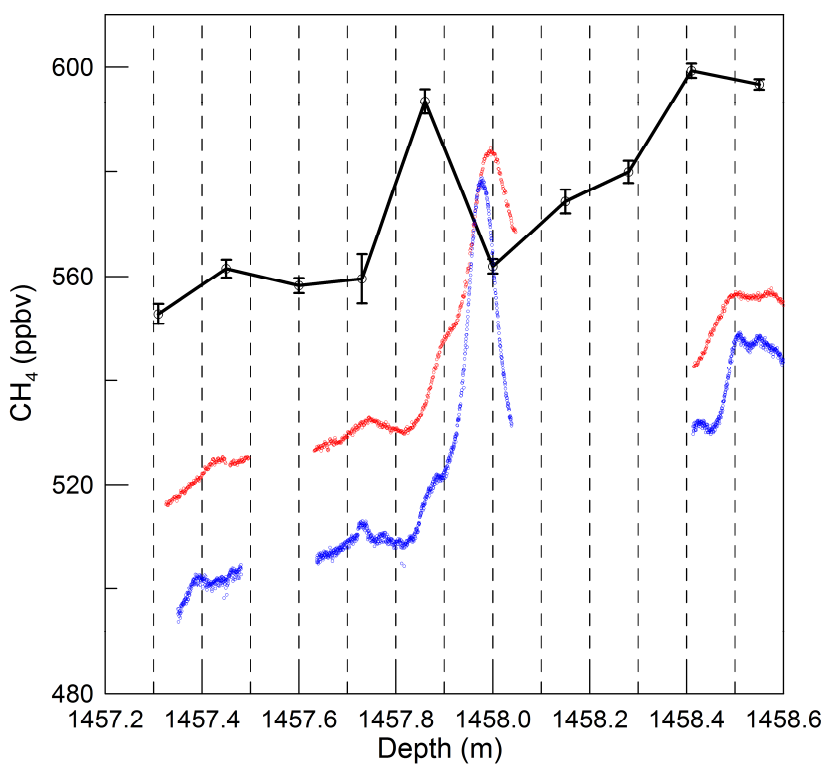

Fig. 4. Zoom over $1.4 \mathrm{~m}$ of the $\mathrm{CH}_{4}$ profiles, located in the Bølling/Allerød - Younger Dryas transition. Discrete OSU measurements (black circles with error bars) show a small depth shift with the WS-CRDS (red dots) and OF-CEAS (blue dots) uncorrected raw data on their respective depth scales.

\section{Methane data sets on a depth scale and uncertainty}

Contamination is removed manually from the ice core measurement. In the example shown in Fig. 2, ambient air entered the experimental setup through the melt head at the time when a core break was melted at a depth of $1773.357 \mathrm{~m}$. In addition to contamination from core breaks, OF-CEAS and WS-CRDS data sets were cleaned due to occasional problems related to the spectral fit or the transfer line (usually at the debubbler level).

As the two depth axes in Fig. 2 show, there is uncertainty in the attribution of the final depth. Notably, depending on where the bottom depth is defined in the time domain, a shift of a few centimetres can occur between the two series. To evaluate this possibility, we compare the two CFA-coupled spectroscopic methane series in the depth domain with discrete $\mathrm{CH}_{4}$ measurements performed at OSU (for the analytical procedure, see e.g. Mitchell et al., 2011) on parallel ice sticks from the same NEEM core. The comparison is illustrated in Fig. 4 with a peculiar $\mathrm{CH}_{4}$ peak located at the transition from the Bølling/Allerød (B/A) to the Younger Dryas (YD). From baseline to baseline, the peak width is $\sim 30 \mathrm{~cm}$. Although the spatial resolution of discrete measurements (with replicate measurements for the peak value) does not provide yet a very precise estimate, a small depth shift of $\sim 15 \mathrm{~cm}$ appears between CFA-coupled spectroscopic and discrete data. On the other hand, the OF-CEAS and WSCRDS series agree within $\pm 3 \mathrm{~cm}$ on the location of the $\mathrm{CH}_{4}$ maximum. Considering the shift with discrete data in this

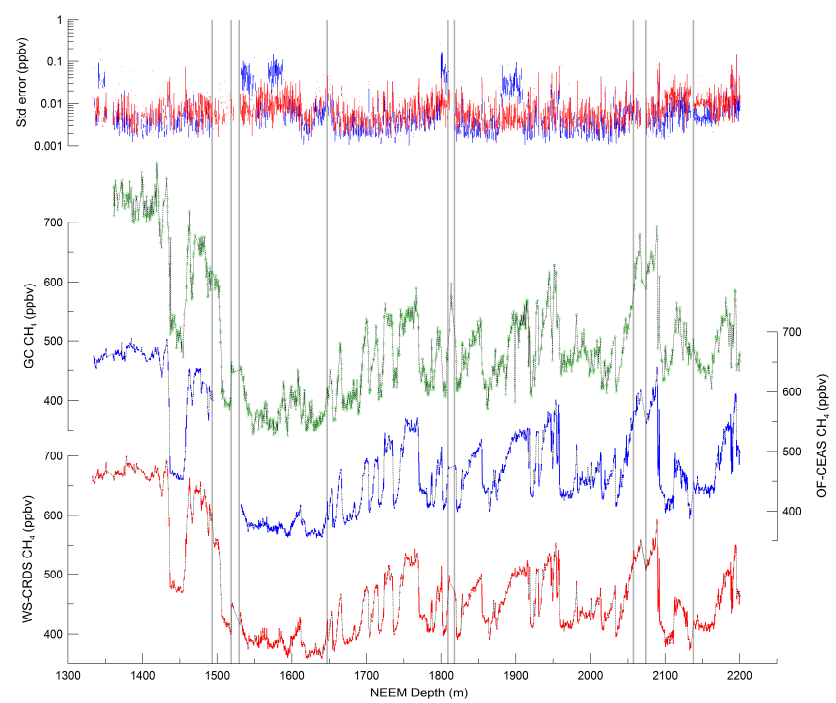

Fig. 5. Lower graphs: WS-CRDS (red), OF-CEAS (blue) and GC (green) data sets in the depth domain before applying mixing ratio corrections. Dashed black lines fill the gaps in each data set. The OF-CEAS and WS-CRDS data are averaged on $20 \mathrm{~cm}$ increments. Vertical grey lines correspond to depths where a change in the analytical setup took place, which affected the results (Table 1). Upper graph: standard error of the mean for each $20 \mathrm{~cm}$ increment (blue: OF-CEAS; red: WS-CRDS).

specific case, in the following we conservatively estimate the depth uncertainty of the two CFA-coupled spectroscopic methane series as $\pm 20 \mathrm{~cm}$.

As illustrated in Fig. 2, the OF-CEAS instrument - and to a lesser extent the WS-CRDS, which sees a smoother signal - registered periodic $\mathrm{CH}_{4}$ changes at a typical scale of $10-15 \mathrm{~cm}$, with an amplitude of 1 to 5 ppbv. In some extreme and rare cases, the peak amplitude could reach 20 ppbv. These changes are not due to the instrument, and do not reflect real structures in the ice core record. Instead they may result from changes in the permeation conditions at the MicroModule (pressure and membrane wetness changes). Unfortunately we could not define an exact way to correct for these periodic changes using, for example, the pressure or the flow rate measurements. To avoid over-interpretation of the record, we therefore smoothed out the periodic changes by averaging each laser spectrometer data set in the depth domain on $20 \mathrm{~cm}$ increments. In the following, the two data sets will be discussed using $20 \mathrm{~cm}$ increment averages. Rates of change will be calculated using the raw data, however, because of the abruptness of some of the D/O transitions.

Figure 5 compares the results from the three instruments as a function of depth. Grey vertical lines indicate system changes, which affected the measurements (Table 1). The main technical problems affecting the measurements appear to be the following: 
- The last deglaciation fully measured by WS-CRDS and GC, but not by OF-CEAS.

- The depth range 1809-1818 m (GIS11 peak) being missed or contaminated (GC).

- The depth range 2074-2138m (GIS22 to GIS21) showing results from the laser spectrometers that are lower than expected due to water vapour in the gas transfer lines.

The three instruments nicely depict the well-known sequence of $\mathrm{CH}_{4}$ changes in the course of GS and GIS successions and of the last deglaciation. Due to the lower precision of the instrument, the GC data set contains more noise (uncertainty on individual measurements of 15-20 ppbv). As seen in the upper part of Fig. 5, the standard error of the mean for each $20 \mathrm{~cm}$ step in the CFA-coupled spectroscopic methane series usually lies around $0.01 \mathrm{ppbv}$, thanks to the instrument precision and the statistics provided by measurements every 1 to $2 \mathrm{~s}$ (equivalent to a theoretical depth resolution of 0.5 to $1 \mathrm{~mm}$ ). The OF-CEAS standard error is usually slightly better than the one of the WS-CRDS because of a faster acquisition rate improving the statistics. At some depth ranges, the OF-CEAS standard error degrades up to $0.1 \mathrm{ppbv}$ due to the binning time inadvertently set to $10 \mathrm{~s}$ by the field operator. In any case, the performances of both laser instruments reach an unprecedented level, implying that very fine structures in the atmospheric $\mathrm{CH}_{4}$ signal can be confidently revealed and discussed for the first time. In the following, we will only discuss the results obtained with the laser instruments.

Figure 5 also shows that the exact $\mathrm{CH}_{4}$ mixing ratio at any given depth significantly differs between the three instruments. As already discussed in previous papers based on CFA and laser spectroscopic $\mathrm{CH}_{4}$ measurements (Stowasser et al., 2012; Rhodes et al., 2013), the raw data sets from laser instruments are biased, essentially due to the difficulty in calibrating the efficiency of the gas extraction along a CFA line. In addition, a shift toward lower values is observed in the WS-CRDS data set between 1493.25 and $1518.55 \mathrm{~m}$ depth, as the OF-CEAS instrument was put offline, reducing the small leakage upstream of the WS-CRDS cavity. The depth range 2074-2138 $\mathrm{m}$ shows a downward shift of the $\mathrm{CH}_{4}$ mixing ratio compared with preceding and following depths due to the presence of water vapour in the laser cavities diluting the sample gas. The water vapour measurement by the two laser instruments did not allow for a suitable correction. Section 8 will explain how we used discrete $\mathrm{CH}_{4}$ measurements along different Greenland ice cores to correct the laser spectrometer data sets for bias on the absolute mixing ratio.

\section{From a depth scale to an age scale}

The NEEM ice and gas chronology is presented in detail in a companion paper (Rasmussen et al., 2013). Briefly, the ice chronology is matched to the Greenland Ice Core Chronology 2005 (GICC05) using 700 match points from electrical conductivity profiles conducted on the NGRIP and NEEM cores. The difference of age between the trapped gases and the surrounding ice ( $\Delta$ age; its modern value is $182+3 /-9 \mathrm{yr}$; Buizert et al., 2012) is calculated using two firn densification models. Climatic input parameters of the models are adjusted to fit independent evaluations based on the isotopic composition of molecular nitrogen $\left(\delta^{15} \mathrm{~N}\right.$ of $\left.\mathrm{N}_{2}\right)$. The $\mathrm{CH}_{4}$ profiles presented here are used as an additional constraint on the models. The onset of $\mathrm{GIS} \mathrm{CH}_{4}$ rises is used assuming either that the midpoint of each $\mathrm{CH}_{4}$ transition lags the water isotope transition by $30 \mathrm{yr}$ or assuming no lag for GIS11 and GIS10 and for the deglaciation (Rasmussen et al., 2013). As a consequence, discussing the precise phase relationship between Greenland climate and $\mathrm{CH}_{4}$ changes would lead to a circular argument, and is not considered here. This will be possible in future when more detailed $\delta^{15} \mathrm{~N}$ of $\mathrm{N}_{2}$ and chemistry data will be available.

\section{$8 \mathrm{CH}_{4}$ mixing ratio correction}

The two raw laser spectroscopic $\mathrm{CH}_{4}$ data sets differ from each other on an absolute scale, and are in general lower than discrete measurements on parallel ice sticks (upper left panel of Fig. 6). It mostly reflects the larger solubility coefficient of methane versus nitrogen and oxygen in water. Note that solubility equilibrium is not necessarily reached during water/gas transfer from the CFA melt head to the MicroModule. Differences between OF-CEAS and WS-CRDS result from a small and variable leak at the outlet of the OFCEAS cavity. In addition, the OF-CEAS instrument was calibrated against CSIRO synthetic air standards before being implemented in the field, which was not the case for the WS-CRDS instrument.

Corrections are thus required to bring the laser spectroscopic data sets to an absolute scale. Contrary to recent laboratory measurements on NEEM ice combining OF-CEAS and CFA analyses (Rhodes et al., 2013), the NEEM 2010 field setup did not include calibration through a full loop system where a mixture of standard gas and degassed water would follow the same transfer line as the sample from the melt head to the spectrometers. Using this method, Rhodes et al. (2013) ran $338 \mathrm{~m}$ of NEEM-S1 core in four weeks with a stable analytical system, allowing for them to evaluate a reliable and stable correction factor (solubility) of 1.079 to the entire data set and to put it on an absolute scale through internal calibration.

During the eight weeks of coupled CFA-gas measurements of the NEEM 2010 field campaign, several changes affecting the analytical setup were made (Table 1). Notably, a small leak of the OF-CEAS gas outlet introduced a contamination of the sample, increasing with a varying but small amount ( $\sim 5$ to $10 \%)$ the measured concentration from the 

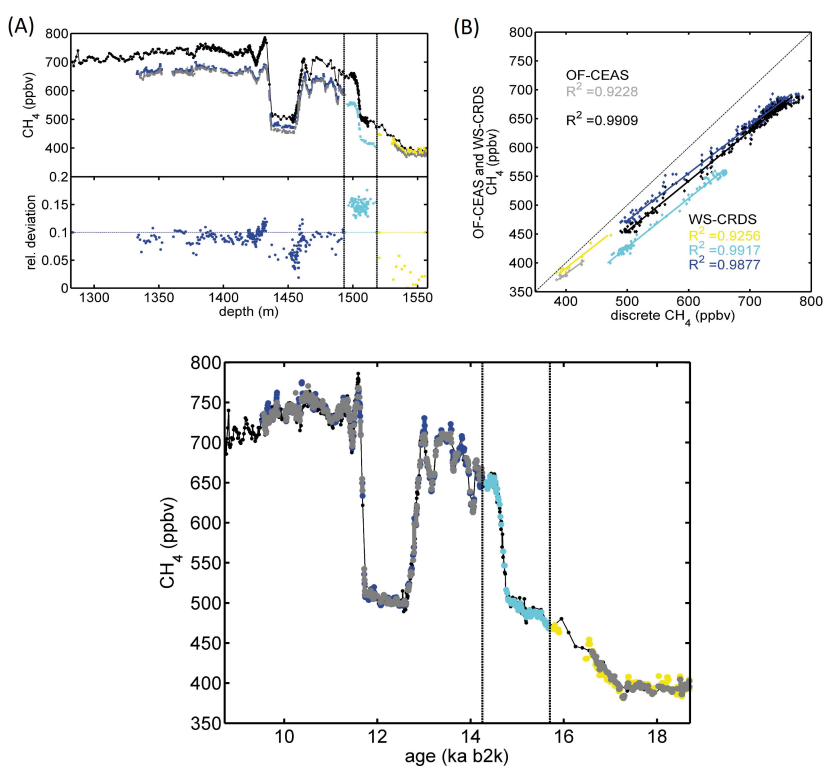

Fig. 6. Upper left panel: (A) $\mathrm{CH}_{4}$ mixing ratio over the NEEM section covering the last deglaciation and the early Holocene, obtained by OF-CEAS (grey symbols) and WS-CRDS (dark-blue, light-blue and yellow symbols) with the continuous-flow system, before mixing ratio correction, and by discrete measurements at OSU on parallel ice slices (black symbols). (B) Relative deviation between WSCRDS and discrete data. Upper right panel: correlation between discrete (OSU), OF-CEAS and WS-CRDS data (same symbols). Lower panel: the three data sets after correction (same symbols).

WS-CRDS (and GC) measurements. This can be seen, for example, for the WS-CRDS data that were measured without the OF-CEAS being connected upstream (light blue in Fig. 6). During the YD event the relative deviation of WSCRDS data with discrete ones is larger on average, suggesting that the contamination due to the small leak at the OF-CEAS outlet had a larger effect on low mixing ratios. Decreasing efficiency followed by replacement of the MicroModule and the temporary removal of the Nafion drying membrane (broken) also contributed to major shifts in the $\mathrm{CH}_{4}$ data sets. $\mathrm{CH}_{4}$ mixing ratios obtained on the Air Liquide standard gas in close loop mode did not allow for us to obtain a reliable correction for bringing the laser spectroscopic data sets into agreement with discrete measurements, as it did not replicate the exact path followed by the sample gas (Rhodes et al., 2013).

In order to place the laser spectroscopic data sets on an absolute scale, as illustrated in Fig. 7, we proceeded as follows:

- Discrete $\mathrm{CH}_{4}$ measurements along the Greenland GRIP (Dällenbach et al., 2000; Blunier and Brook, 2001; Flückiger et al., 2004), GISP2 (Brook et al., 1996; Grachev et al., 2007; unpublished data), NGRIP (Capron et al., 2012; Flückiger et al., 2004; Huber et al., 2006; Schilt et al., 2010; Baumgartner et al., 2012) and NEEM (2013) ice cores were combined to pro-
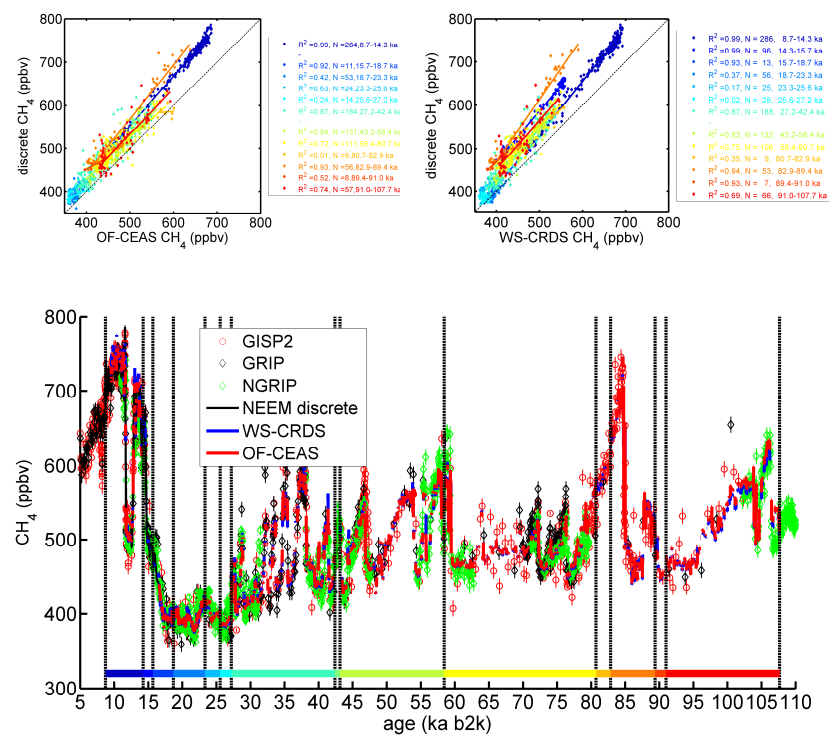

Fig. 7. Upper panels: calibration (with regression coefficient) of the $\mathrm{CH}_{4}$ mixing ratios obtained by OF-CEAS (left) or WS-CRDS (right) on the NEEM core against discrete measurements performed on ice of the same age from GISP2, GRIP, NGRIP and NEEM ice cores. Lower panel: comparison of CFA-coupled spectroscopic $\mathrm{CH}_{4}$ profiles and discrete measurements after calibration. Colour lines at the bottom illustrate the depth intervals where the individual calibrations apply. Vertical black lines correspond to system changes (Table 1).

duce a reference Greenland $\mathrm{CH}_{4}$ curve over the time period of interest. Discrete $\mathrm{CH}_{4}$ measurements from different cores were put on the same $\mathrm{CH}_{4}$ standard scale, i.e. NOAA04 (Dlugokencky et al., 2005) used for GISP2. All data sets use the same gas chronology (GICC05modelext).

- Independent calibration curves were determined for each NEEM depth interval in between analytical system changes (Table 1) and for each laser instrument (upper panels of Fig. 7). The OF-CEAS and WSCRDS data sets were then corrected using these calibration curves.

The resulting corrections provide a reasonable agreement between all available Greenland $\mathrm{CH}_{4}$ measurements over the glaciation and deglaciation (lower panel of Fig. 7). However one should be careful when interpreting the CFAcoupled spectroscopic methane series on an absolute scale. Firstly, excellent calibration could only be performed over the deglaciation and early Holocene using discrete OSU measurements (having a pooled standard deviation of only $4.3 \mathrm{ppbv}$ on individual results) on the same core (Fig. 6). The same holds for GIS21 to GIS19 (discrete data from Grachev et al., 2007, 2009), although there is an additional uncertainty associated with the chronological fit between GISP2 and NEEM. For other sections, the correction often relies on 

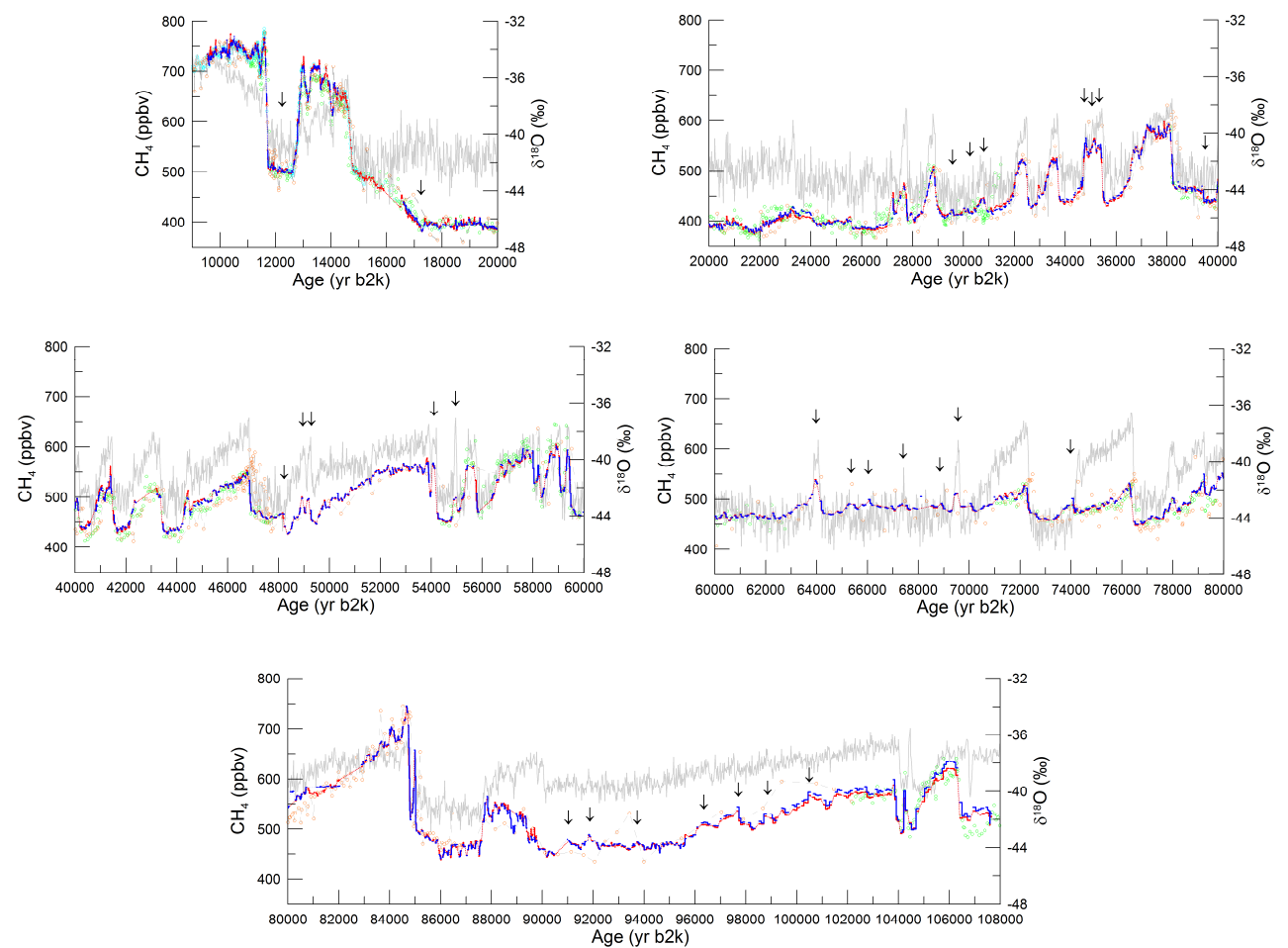

Fig. 8. NEEM CFA-coupled spectroscopic methane mixing ratios (averaged over $20 \mathrm{~cm}$ increments: OF-CEAS in dark blue, WS-CRDS in red) compared with discrete $\mathrm{CH}_{4}$ results from the NGRIP (green circles), GISP2 (orange circles) and NEEM (light-blue circles) ice cores. The background grey curve corresponds to the $\delta^{18} \mathrm{O}$ water isotope profile measured along the NGRIP ice core, shown on the GICC05modelext time scale (North Greenland Ice Core Project members, 2004). Arrows correspond to atmospheric $\mathrm{CH}_{4}$ changes or trends revealed with the high-resolution laser spectroscopic data and not yet observed with existing discrete measurements on Greenland ice cores (Sect. 9). The arrow at $74 \mathrm{ka} \mathrm{b} 2 \mathrm{k}$ points to the $\mathrm{CH}_{4}$ peak concomitant with the Toba eruption.

a limited number of discrete measurements with a worse experimental uncertainty than those from OSU. This amplifies possible biases on the absolute scale of our record due to different blanks, standard reference and/or age scales used in each discrete data set. In addition, one cannot exclude small drifts of the CFA analytical system in between changes (Table 1). Overall we are confident that the laser spectroscopic data sets can be interpreted in terms of the fine signal structure, exact location of mixing ratio changes and rate of changes - all these being estimators which are essentially independent of the $\mathrm{CH}_{4}$ scale used. However caution should be taken when comparing average CFA-coupled spectroscopic $\mathrm{CH}_{4}$ mixing ratios, e.g. in between interstadials.

\section{New features compared with discrete measurements}

We compare in Fig. 8 the laser spectroscopic $\mathrm{CH}_{4}$ data sets with available discrete measurements performed along NGRIP, GISP2 and NEEM. For the sake of clarity, we divide the comparison into five panels covering (1) marine isotope stage (MIS) 2, the last deglaciation and the early Holocene; (2) the late part of MIS 3 including GIS8 to GIS2; (3) the early part of MIS 3 with GIS17 to GIS9; (4) MIS 4 with the end of GIS21 and GIS20 to GIS18; and (5) MIS 5d to 5a encompassing GIS24 to GIS21. GRIP data are not shown, as their resolution and accuracy do not improve the visual comparison.

One benefit of the CFA-coupled spectroscopic methane series is to provide for the first time a high-resolution record over time periods when existing Greenland records have a relatively poor temporal resolution. This is notably the case for the long sequences between GIS23 and the onset of GIS21, between GIS19 and GIS17, and the long GIS14.

A second major advantage lies in the degree of details revealed in the atmospheric methane evolution. Thanks to the remarkable standard error obtained on $20 \mathrm{~cm}$ depth increments from the raw data, small variations and trends unnoticed in previous records (arrows in Fig. 8) can now be recognized. We list below the most striking ones going backward in time:

- The Younger Dryas is characterized by a remarkably reduced $\mathrm{CH}_{4}$ variability (22 ppbv peak to peak) and a small increase during the course of the event ( $7 \mathrm{ppbv})$, both being confirmed by discrete OSU measurements (Fig. 6). 
Table 2. Stratigraphic markers in the gas phase of the NEEM core, associated with specific atmospheric $\mathrm{CH}_{4}$ events.

\begin{tabular}{|c|c|c|c|c|c|c|c|c|c|c|c|}
\hline $\begin{array}{l}\text { Event in } \\
\text { Rasmussen et al. } \\
\text { (2013) }\end{array}$ & $\begin{array}{l}\mathrm{CH}_{4} \\
\text { depth (m) }\end{array}$ & $\begin{array}{l}\text { Additional event } \\
\text { (2013) }\end{array}$ & $\begin{array}{l}\mathrm{CH}_{4} \text { depth } \\
\text { (m) }\end{array}$ & $\begin{array}{l}\text { Event in } \\
\text { Rasmussen } \\
\text { et al. (2013) }\end{array}$ & $\begin{array}{l}\mathrm{CH}_{4} \text { depth } \\
\text { (m) }\end{array}$ & $\begin{array}{l}\text { Additional event } \\
\text { (2013) }\end{array}$ & $\begin{array}{l}\mathrm{CH}_{4} \text { depth } \\
\text { (m) }\end{array}$ & $\begin{array}{l}\text { Event in } \\
\text { Rasmussen } \\
\text { et al. (2013) }\end{array}$ & $\begin{array}{l}\mathrm{CH}_{4} \text { depth } \\
(\mathrm{m})\end{array}$ & $\begin{array}{l}\text { Additional event } \\
\text { (2013) }\end{array}$ & $\begin{array}{l}\mathrm{CH}_{4} \text { depth } \\
\text { (m) }\end{array}$ \\
\hline & & minimum PB oscillation & 1425.55 & & & peak DO7b & 1724.40 & & & start DO15 & 1930.84 \\
\hline "PB oscillation" & 1425.20 & & & "DO7b" & 1724.90 & & & & & peak 2 DO16 & 1946.84 \\
\hline \multirow[t]{3}{*}{ "YD-PB" } & 1435.50 & & & & & peak D07 & 1734.83 & & & peak 1 DO16 & 1948.38 \\
\hline & & start YD-PB & 1436.93 & "DO7" & 1735.35 & & & "DO16" & 1948.56 & & \\
\hline & & end BA-YD & 1454.50 & 'DO8b" & 1748.00 & & & "DO17.1" & 1954.75 & & \\
\hline "BA-YD" & 1458.20 & & & "DO8" & 1769.80 & & & & & peak DO17 & 1957.63 \\
\hline "BA1" & 1466.40 & & & & & start DO8 & 1770.34 & "DO17" & 1958.10 & & \\
\hline "BA2" & 1478.90 & & & "DO9" & 1787.95 & & & & & start DO17 & 1958.54 \\
\hline "BA3" & 1488.00 & & & & & start DO9 & 1788.58 & "DO18" & 1982.05 & & \\
\hline \multirow[t]{3}{*}{ "OD-BA" } & 1504.40 & & & & & peak DO10 & 1800.71 & & & start DO18 & 1982.56 \\
\hline & & start OD-BA & 1506.22 & "DO10" & 1801.50 & & & "DO19.1" & 2001.68 & & \\
\hline & & start TI & 1541.29 & "DO11" & 1820.10 & & & "DO19" & 2014.14 & & \\
\hline \multirow[t]{4}{*}{ "DO2" } & 1612.20 & & & & & start DO11 & 1820.61 & & & start DO19 & 2014.4 \\
\hline & & start rapid ramp DO2 & 1612.81 & & & peak DO12b & 1828.31 & & & end DO20 & 2017.48 \\
\hline & & start slow ramp DO2 & 1619.39 & "DO12b" & 1829.00 & & & "DO21b" & 2019.55 & & \\
\hline & & end DO3 & 1640.56 & "DO12" & 1854.62 & & & & & peak DO20 & 2032.48 \\
\hline \multirow[t]{3}{*}{ "DO3" } & 1654.45 & & & & & start DO12 & 1855.09 & "DO20" & 2033.40 & & \\
\hline & & start DO3 & 1654.88 & "DO13" & 1873.25 & & & & & start DO20 & 2033.98 \\
\hline & & end DO4 & 1656.78 & & & start DO13 & 1873.54 & "DO21b" & 2048.20 & & \\
\hline \multirow[t]{4}{*}{ "DO4" } & 1666.72 & & & & & end DO14 & 1874.81 & & & peak DO21 & 2089.12 \\
\hline & & peak $3 \mathrm{GS} 4$ & 1674.67 & & & peak 2 DO14 & 1915.54 & "DO21" & 2089.95 & & \\
\hline & & end peak 1 GS4 & 1681.14 & & & valley DO14 & 1717.52 & & & start DO21 & 2090.39 \\
\hline & & start peak $1 \mathrm{GS} 4$ & 1685.49 & & & peak 1 DO14 & 1918.50 & & & start pre-DO21 & 2092.46 \\
\hline "DO4.1" & 1684.55 & & & 'DO14' & 1919.20 & & & & & end $\mathrm{DO} 22$ & 2110.60 \\
\hline \multirow[t]{3}{*}{ "DO5" } & 1702.80 & & & & & start DO14 & 1919.72 & "DO22b" & 2112.00 & & \\
\hline & & start DO5 & 1705.23 & & & end DO15.1 & 1923.06 & & & peak DO23 & 2187.72 \\
\hline & & peak DO6 & 1714.95 & "DO15.1" & 1924.60 & & & & & start $\mathrm{DO} 23$ & 2188.44 \\
\hline \multirow[t]{3}{*}{ "DO6" } & 1715.55 & & & & & start DO15.1 & 1924.91 & & & end pre-DO23 & 2189.03 \\
\hline & & start DO6 & 1716.33 & & & end DO15.1 & 1925.22 & & & peak pre-DO23 & 2189.19 \\
\hline & & end DO7 & 1719.78 & "DO15" & 1930.45 & & & & & end DO24 & 2190.40 \\
\hline
\end{tabular}

- The end of the glaciation in the methane signal is punctuated by a sharp dip centred at $17.27 \mathrm{ka} \mathrm{b} 2 \mathrm{k}$, and provides a clear gas marker for the start of the deglacial sequence.

- Three $\mathrm{CH}_{4}$ peaks appear during the GS5 between 29 and $31 \mathrm{ka} \mathrm{b} 2 \mathrm{k}$, with amplitudes of 10 to $25 \mathrm{ppbv}$ and durations of 200 to $400 \mathrm{yr}$. Only the oldest one centred at $30.7 \mathrm{ka} \mathrm{b} 2 \mathrm{k}$ sees a significant counterpart in the water isotopic profile of NGRIP.

- GIS7 reveals three $\mathrm{CH}_{4}$ maxima.

- The two methane plateaus preceding the onsets of GIS8 and GIS12 appear more stable than in existing discrete records, and are established following a sharp increase.

- New sub-millennial $\mathrm{CH}_{4}$ peaks associated with similar changes in the water isotopic profile are clearly identified with GIS13 (double peak), a precursor of GIS14 centred at $55 \mathrm{ka}$ b2k, GIS18 and a series of smallamplitude events between 65 and $70 \mathrm{ka} \mathrm{b} 2 \mathrm{~K}$.

- The long downward sequence between GIS23 and GS22 is punctuated by several sub-millennial $\mathrm{CH}_{4}$ peaks with amplitudes in the 10-25 ppbv range.
The new laser spectroscopic $\mathrm{CH}_{4}$ data sets also nicely confirm a 25 ppbv peak culminating at $74.1 \mathrm{ka} \mathrm{b} 2 \mathrm{k}$, already suggested in the GISP2 (Grachev et al., 2009) and GRIP (Flückiger et al., 2004) discrete data sets. This takes place at the transition between GIS20 and GS19, and spans nearly one millennium. With its onset concomitant with the Toba eruption in Indonesia (Svensson et al., 2013), one of the largest in the Quaternary era, the methane peak raises questions on the possible mechanistic interplay between the two events. The climatic impact of the Toba eruption is expected to have lasted a few years at most (Bekki et al., 1996), similar to the recent Pinatubo eruption. In addition, large volcanic eruptions with stratospheric plumes are expected to lower (instead of increasing) the $\mathrm{CH}_{4}$ mixing ratio according to coupled climate-chemistry models (Bekki and Law, 1997; Bândă et al., 2013).

\section{Depth-age markers}

A typical use of detailed $\mathrm{CH}_{4}$ profiles lies in crosscorrelation of different ice cores and stratigraphic tuning of their chronology in the gas phase. So far, notably due to the difficulty in defining the exact onset and end of methane transitions in discrete profiles, the midpoint of transitions was used for that purpose. The laser spectroscopic data sets 
presented here were exploited this way for building a preliminary NEEM chronology (Rasmussen et al., 2013).

Indeed a major advantage of the CFA is that it provides the precise location of slope changes. We make use of this to list a full suite of NEEM stratigraphic markers in the gas phase (Table 2), which could be further valorized when more continuous-flow profiles (or very detailed and precise discrete measurements) of atmospheric methane will be available from other cores, or, for example, in detailed comparison between the $\mathrm{CH}_{4}$ record and speleothem profiles related to climate/humidity changes in the major source regions of atmospheric methane. Due to interruptions in the profile when the sample gas was mixed with standard gas, some transitions cannot be identified with better than a $\sim \pm 50 \mathrm{~cm}$ accuracy, and are therefore not mentioned. In addition, the transition from a GIS to a GS is often slow and does not always provide a clear marker. The same holds for some GIS peaks their sharpness not being as pronounced as the GIS onset.

The uncertainty associated with each marker as listed in Table 2 is $\pm 20 \mathrm{~cm}$.

Some additional features could be considered in future work, taking into account the 10-20 ppbv variability punctuating a GIS or GS sequence and by optimizing the correlation with other records over the full duration of the sequence instead of a single event as listed in Table 2.

\section{Rate of $\mathrm{CH}_{4}$ change}

The exceptional depth resolution of the CFA-coupled spectroscopic $\mathrm{CH}_{4}$ profiles allows for us to confidently investigate the rate of $\mathrm{CH}_{4}$ change associated with the main signal features, i.e. GIS onsets and ends as well as the deglaciation. The averaging over $20 \mathrm{~cm}$ increments conducted on the raw data can smooth out some rapid events. For instance, the onset of GIS17 is entirely recorded in a single $110 \mathrm{~cm}$ long run. We therefore determine the first derivative on raw data after calibration to discrete measurements (Sect. 8) and transfer to the GICC05modelext time scale (Sect. 7).

The upper graph of Fig. 9 shows the resulting first derivative on both laser spectroscopic $\mathrm{CH}_{4}$ profiles. Note the larger (positive or negative) rate of change generated by the OFCEAS instrument on the most rapid events, due to its shorter sweeping time. Most GIS events (with the exception of GIS22 and GIS9) display a larger rate of $\mathrm{CH}_{4}$ increase (onset) or growth rate than the subsequent rate of decrease (transition toward the following GS). The same holds in general for the water isotopic record of Greenland interstadials. This indicates that the mechanisms responsible for changes to the $\mathrm{CH}_{4}$ budget at these timescales (e.g. wetland extent and/or $\mathrm{CH}_{4}$ fluxes, oxidative capacity of the atmosphere and biomass burning; see Baumgartner et al., 2012, for a recent review) remained associated to temperature changes as recorded in Greenland.

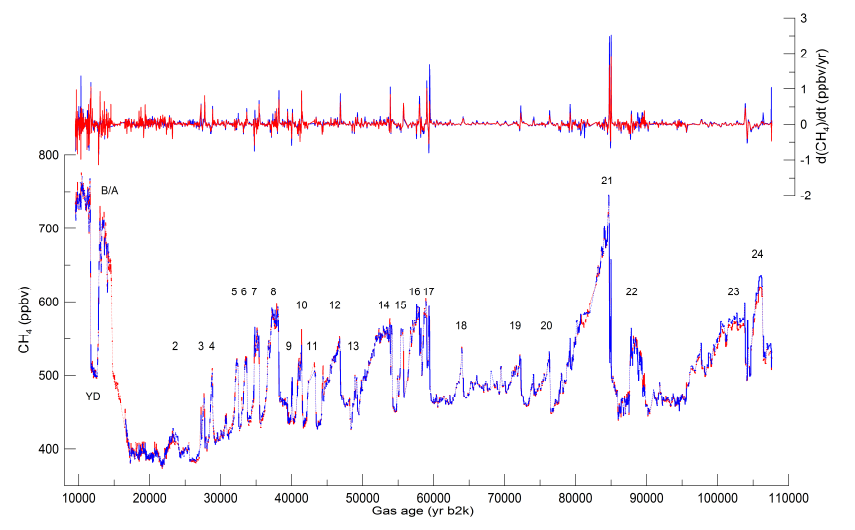

Fig. 9. Calibrated laser spectroscopic $\mathrm{CH}_{4}$ profiles (blue: OF-CEAS; red: WS-CRDS) from 107.7 to $9.5 \mathrm{ka}$ b2k (GICC05mmodelext time scale) and associated rates of $\mathrm{CH}_{4}$ change (same colour code). Numbers correspond to Greenland interstadials (GIS, or Dansgaard-Oeschger events). YD stands for Younger Dryas, and B/A for Bølling/Allerød.

Figure 9 also illustrates a generally decreasing trend to the $\mathrm{CH}_{4}$ growth rate, from 1.7 to $0.6 \mathrm{ppbv} \mathrm{yr}^{-1}$, in the course of GIS events characterizing MIS3. This is not accompanied with a similar trend in the amplitude of $\mathrm{CH}_{4}$ changes, nor in the derivative of the water isotopic profile. For instance, GIS8 has a comparable amplitude to GIS17, whereas its $\mathrm{CH}_{4}$ growth rate is 1.7 times smaller. It suggests that the progressive cooling accompanying MIS3 had a buffering effect on the methane sources/sinks response time to climate changes. Aside from temperature, alternative sources of $\mathrm{CH}_{4}$ emission buffering could also be considered, such as the strength of Heinrich events, the monsoon intensity, sea level or the AMOC structure and strength, all affecting continental hydrology.

The largest growth rate is observed with the GIS21 onset and its precursor event at $85 \mathrm{ka} \mathrm{b} 2 \mathrm{k}$, reaching $2.5 \mathrm{ppbv} \mathrm{yr}^{-1}$. This is nearly four times larger than the average growth rate previously determined on the same events using detailed discrete $\mathrm{CH}_{4}$ measurements along the GISP2 ice core (Grachev et al., 2009). We note that it is comparable to the rate of increase observed in the 1990s, when anthropogenic sources tended to stabilize (Dlugokencky et al., 1998). On the other hand the growth rate that we deduce for GIS19 and GIS20, i.e. 0.4 to $0.5 \mathrm{ppbv} \mathrm{yr}^{-1}$, is similar to the GISP2 estimate.

The growth rates given here may be minimal estimates of the true atmospheric growth rate due to (1) the smoothing related to gas diffusion in firn and trapping in ice (e.g. Buizert et al., 2012) and (2) the smoothing effects associated with the continuous flow method (see above). The second effect would tend to reduce the calculated rate of $\mathrm{CH}_{4}$ change with depth as ice thinning reduces the average annual layer thickness. We indeed observe the opposite trend over MIS3, suggesting that this second effect is probably minor. Future comparisons with high-resolution discrete $\mathrm{CH}_{4}$ measurements 
along the NEEM core will constrain this smoothing effect due to the continuous flow method. In addition, future detailed $\delta^{15} \mathrm{~N}$ of $\mathrm{N}_{2}$ measurements over some of these $\mathrm{CH}_{4}$ transitions will help to evaluate how much smoothing due to gas diffusion and trapping impacted our estimates of methane rates of change.

\section{Conclusions}

CFA-coupled measurements of the $\mathrm{CH}_{4}$ mixing ratio in ice cores using laser instruments for trace-gas analysis offer considerable improvement of our knowledge regarding past atmospheric methane changes. Although the method is not perfect because of the partial loss of a small fraction of the sample signal due smoothing effects associated with sample dispersion and memory effects in the experimental setup, and because of difficulties in calibrating the system in order to obtain absolute values, it provides a remarkable precision and depth resolution in a time-efficient manner and without dedicating specific ice core sub-samples.

The first field application of the method during the NEEM 2010 campaign provides us with new insights about the methane variability at sub-millennial time scale in the course of the last glaciation and deglaciation. It reveals that submillennial $\mathrm{CH}_{4}$ variability is quasi-systematic along the record. The new methane record can be used in the future for very detailed comparison with other climate proxies, notably from methane source regions, as well as to discuss further the possible mechanisms responsible for rapid but small changes. Numerous and very precise (with $\pm 20 \mathrm{~cm}$ depth uncertainty) stratigraphic markers are provided by the CFAcoupled spectroscopic $\mathrm{CH}_{4}$ profiles, which will be useful for finely tuning the ice core chronologies and their link with other archives (notably speleothems).

Lastly, the quasi-continuous time sequence obtained by CFA and laser spectrometric analysis allows us for the first time to quantify in a systematic manner the $\mathrm{CH}_{4}$ rate of change as recorded in the ice. The latter remains a minimal estimate of the true signal in the atmosphere due to smoothing during gas diffusion and trapping in the firn. Further work, with other tracers and the combination of CFA-coupled spectroscopic methane series from cores with different firn conditions, should improve this first attempt.

Acknowledgements. This work was supported by the Past4Future project from the European Commission's Seventh Framework Programme under grant agreement no. 243908, and is Past4Future contribution number 58. It also received funding from the European Research Council under the European Community's Seventh Framework Programme FP7/2007-2013 grant agreement no. 291062 (project ICE\&LASERS). Additional support was provided by the French ANR programmes NEEM (ANR-07VULN-09-001) and IMPACT-BOREAL (ANR-06-VULN-0011), US NSF grant OPP-0806414, an NSF Graduate Research Fellowship (J. Rosen) and the Swiss National Science Foundation.
Grateful thanks go to the NEEM community for logistics, drilling, science and other support. We also thank all NEEM scientists and students in the science trench for assistance in processing the core in the field and for handling the CFA system. The NEEM project is directed by the Centre for Ice and Climate at the Niels Bohr Institute, Copenhagen, and the US NSF OPP. It is supported by funding agencies and institutions in Belgium (FNRS-CFB and FWO), Canada (NRCan/GSC), China (CAS), Denmark (FIST), France (IPEV, CNRS/INSU, CEA and ANR), Germany (AWI), Iceland (RannIs), Japan (NIPR), Korea (KOPRI), the Netherlands (NWO/ALW), Sweden (VR), Switzerland (SNF), the United Kingdom (NERC) and the USA (US NSF, OPP).

Edited by: G. Winckler

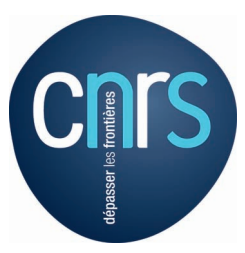

The publication of this article is financed by CNRS-INSU.

\section{References}

Bândă, N., Krol, M., van Weele, M., van Noije, T., and Röckmann, T.: Analysis of global methane changes after the 1991 Pinatubo volcanic eruption, Atmos. Chem. Phys., 13, 22672281, doi:10.5194/acp-13-2267-2013, 2013.

Baumgartner, M., Schilt, A., Eicher, O., Schmitt, J., Schwander, J., Spahni, R., Fischer, H., and Stocker, T. F.: High-resolution interpolar difference of atmospheric methane around the Last Glacial Maximum, Biogeosciences, 9, 3961-3977, doi:10.5194/bg-93961-2012, 2012.

Bekki, S. and Law, K. S.: Sensitivity of the atmospheric $\mathrm{CH}_{4}$ growth rate to global temperature changes observed from 1980 to 1992 , Tellus Ser. B, 49, 409-416, 1997.

Bekki, S., Pyle, J. A., Zhong, W., Toumi, R., Haigh, J. D., and Pyle, D. M.: The role of microphysical and chemical processes in prolonging the climate forcing of the Toba eruption, Geophys. Res. Lett., 23, 2669-2672, 1996.

Blunier, T. and Brook, E. J.: Timing of Millennial-Scale climate change in Antarctica and Greenland during the last glacial period, Science, 291, 109-111, 2001.

Blunier, T., Chappellaz, J., Schwander, J., Dällenbach, A., Stauffer, B., Stocker, T. F., Raynaud, D., Jouzel, J., Clausens, H. B., Hammer, C. U., and Johnsen, S. J.: Asynchrony of Antarctic and Greenland climate change during the last glacial period, Nature, 394, 739-743, 1998.

Brook, E. J., Sowers, T., and Orchardo, J.: Rapid variations in atmospheric methane concentration during the past 110000 years, Science, 273, 1087-1091, 1996.

Buizert, C., Martinerie, P., Petrenko, V. V., Severinghaus, J. P., Trudinger, C. M., Witrant, E., Rosen, J. L., Orsi, A. J., Rubino, M., Etheridge, D. M., Steele, L. P., Hogan, C., Laube, J. C., Sturges, W. T., Levchenko, V. A., Smith, A. M., Levin, I., Conway, T. J., Dlugokencky, E. J., Lang, P. M., Kawamura, K., Jenk, T. M., White, J. W. C., Sowers, T., Schwander, J., and Blunier, T.: Gas transport in firn: multiple-tracer characterisation and model 
intercomparison for NEEM, Northern Greenland, Atmos. Chem. Phys., 12, 4259-4277, doi:10.5194/acp-12-4259-2012, 2012.

Capron, E., Landais, A., Chappellaz, J., Buiron, D., Fischer, H., Johnsen, S. J., Jouzel, J., Leuenberger, M., Masson-Delmotte, V., and Stocker, T. F.: A global picture of the first abrupt climatic event occurring during the last glacial inception, Geophys. Res. Lett., 39, L15703, doi:10.1029/2012GL052656, 2012.

Chappellaz, J., Blunier, T., Raynaud, D., Barnola, J.-M., Schwander, J., and Stauffer, B.: Synchronous changes in atmospheric $\mathrm{CH}_{4}$ and Greenland climate between 40 and 8kyr BP, Nature, 366, 443-445, 1993.

Crosson, E. R.: A cavity ring-down analyzer for measuring atmospheric levels of methane, carbon dioxide, and water vapor, Appl. Phys. B, 92, 403-408, 2008.

Dällenbach, A., Blunier, T., Flückiger, J., Stauffer, B., Chappellaz, J., and Raynaud, D.: Changes in the atmospheric $\mathrm{CH}_{4}$ gradient between Greenland and Antarctica during the last glacial and the transition to the Holocene, Geophys. Res. Lett., 27, 1005-1008, 2000.

Dlugokencky, E. J., Masarie, K. A., Lang, P. M., and Tans, P. P.: Continuing decline in the growth rate of the atmospheric methane burden, Nature, 393, 447-450, 1998.

Dlugokencky, E. J., Myers, R. C., Lang, P. M., Masarie, K. A., Crotwell, A. M., Thoning, K. W., Hall, B. D., Elkins, J. W., and Steele, L. P.: Conversion of NOAA atmospheric dry air $\mathrm{CH}_{4}$ mole fractions to a gravimetrically prepared standard scale, J. Geophys. Res.-Atmos., 110, D18306, doi:10.1029/2005JD006035, 2005.

EPICA community members: One-to-one interhemispheric coupling of polar climate variability during the last glacial, Nature, 444, 195-198, 2006.

Etheridge, D. M., Steele, L. P., Francey, R. J., and Langenfelds, R. L.: Atmospheric methane between 1000 A.D. and present: Evidence of anthropogenic emissions and climatic variability, J. Geophys. Res., 103, 15979-15994, 1998.

Faïn, X., Chappellaz, J., Rhodes, R. H., Stowasser, C., Blunier, T., McConnell, J. R., Brook, E. J., Preunkert, S., Legrand, M., Desbois, T., and Romanini, D.: High resolution measurements of carbon monoxide along a late Holocene Greenland ice core: evidence for in-situ production, Clim. Past Discuss., 9, 2817-2857, doi:10.5194/cpd-9-2817-2013, 2013.

Flückiger, J., Blunier, T., Stauffer, B., Chappellaz, J., Spahni, R., Kawamura, K., Schwander, J., Stocker, T. F., and Dahl-Jensen, D.: $\mathrm{N}_{2} \mathrm{O}$ and $\mathrm{CH}_{4}$ variations during the last glacial epoch: insight into global processes, Global Biogeochem. Cy., 16, GB1020, doi:10.1029/2003GB002122, 2004.

Gkinis, V., Popp, T. J., Johnsen, S. J., and Blunier, T.: A continuous stream flash evaporator for the calibration of an IR cavity ringdown spectrometer for the isotopic analysis of water, Isotopes in Environmental and Health Studies, 46, 463-475, 2010.

Grachev, A. M., Brook, E. J., and Severinghaus, J. P.: Abrupt changes in atmospheric methane at the MIS 5b-5a transition, Geophys. Res. Lett., 34, L20703, doi:10.1029/2007GL029799, 2007.

Grachev, A. M., Brook, E. J., Severinghaus, J. P., and Pisias, N. G.: Relative timing and variability of atmospheric methane and GISP2 oxygen isotopes between 68 and $86 \mathrm{ka}$, Global Biogeochem. Cy., 23, GB2009, doi:10.1029/2008GB003330, 2009.
Huber, C., Leuenberger, M., Spahni, R., Flückiger, J., Schwander, J., Stocker, T. F., Johnsen, S., Landais, A., and Jouzel, J.: Isotope calibrated Greenland temperature record over Marine Isotope Stage 3 and its relation to $\mathrm{CH}_{4}$, Earth Planet. Sci. Lett., 243, 504-519, 2006.

Kaufmann, P. R., Federer, U., Hutterli, M. A., Bigler, M., Schupbach, S., Ruth, U., Schmitt, J., and Stocker, T. F.: An Improved Continuous Flow Analysis System for High-Resolution Field Measurements on Ice Cores, Environ. Sci. Technol., 42, 80448050, 2008.

Loulergue, L., Schilt, A., Spahni, R., Masson-Delmotte, V., Blunier, T., Lemieux, B., Barnola, J. M., Raynaud, D., Stocker, T. F., and Chappellaz, J.: Orbital and millennial-scale features of atmospheric $\mathrm{CH}_{4}$ over the past 800,000 years, Nature, 453, 383-386, 2008.

Mitchell, L. E., Brook, E. J., Sowers, T., McConnell, J. R., and Taylor, K.: Multidecadal variability of atmospheric methane, 1000-1800 CE, J. Geophys. Res.-Biogeosci., 116, G02007, doi:10.1029/2010JG001441, 2011.

Nakazawa, T., Machida, T., Tanaka, M., Fujii, Y., Aoki, S., and Watanabe, M.: Antarctic regions in pre-industrial/preagricultural era, Geophys. Res.Lett., 20, 943-946, 1993.

North Greenland Ice Core Project members: High resolution record of Northern Hemisphere climate extending into the last interglacial period, Nature, 2805, 1-5, 2004.

Rasmussen, S. O., Abbott, P., Blunier, T., Bourne, A., Brook, E., Buchardt, S. L., Buizert, C., Chappellaz, J., Clausen, H. B., Cook, E., Dahl-Jensen, D., Davies, S., Guillevic, M., Kipfstuhl, S., Laepple, T., Seierstad, I. K., Severinghaus, J. P., Steffensen, J. P., Stowasser, C., Svensson, A., Vallelonga, P., Vinther, B. M., Wilhelms, F., and Winstrup, M.: A first chronology for the NEEM ice core, Clim. Past Discuss., 9, 2967-3013, doi:10.5194/cpd-92967-2013, 2013.

Rhodes, R. H., Faïn, X., Stowasser, C., Blunier, T., Chappellaz, J., McConnell, J. R., Romanini, D., Mitchell, L. E., and Brook, E. J.: Continuous methane measurements from a late Holocene Greenland ice core: Atmospheric and in-situ signals, Earth Planet. Sci. Lett., 368, 9-19, 2013.

Romanini, D., Chenevier, M., Kassi, S., Schmidt, M., Valant, C., Ramonet, M., Lopez, J., and Jost, H. J.: Optical-feedback cavityenhanced absorption: a compact spectrometer for real-time measurement of atmospheric methane, Appl. Phys., 83, 659-667, 2006.

Rousseau, D. D., Kukla, G., and McManus, J.: What is what in the ice and the ocean?, Quaternary Sci. Rev., 25, 2025-2030, 2006.

Schilt, A., Baumgartner, M., Schwander, J., Buiron, D., Capron, E., Chappellaz, J., Loulergue, L., Schupbach, S., Spahni, R., Fischer, H., and Stocker, T. F.: Atmospheric nitrous oxide during the last 140,000 years, Earth Planet. Sci. Lett., 300, 33-43, 2010.

Schüpbach, S., Federer, U., Kaufmann, P. R., Hutterli, M. A., Buiron, D., Blunier, T., Fischer, H., and Stocker, T. F.: A New Method for High-Resolution Methane Measurements on Polar Ice Cores Using Continuous Flow Analysis, Environ. Sci. Technol., 43, 5371-5376, 2009.

Sowers, T., Brook, E. J., Etheridge, D. M., Blunier, T., Fuchs, A., Leuenberger, M., Chappellaz, J., Barnola, J.-M., Wahlen, M., Deck, B. L., and Weyhenmeyer, C.: An interlaboratory comparison of techniques for extracting and analyzing trapped gases in ice cores, J. Geophys. Res., 102, 26527-26538, 1997. 
Stowasser, C., Buizert, C., Gkinis, V., Chappellaz, J., Schüpbach, S., Bigler, M., Faïn, X., Sperlich, P., Baumgartner, M., Schilt, A., and Blunier, T.: Continuous measurements of methane mixing ratios from ice cores, Atmos. Meas. Tech., 5, 999-1013, doi:10.5194/amt-5-999-2012, 2012.
Svensson, A., Bigler, M., Blunier, T., Clausen, H. B., Dahl-Jensen, D., Fischer, H., Fujita, S., Goto-Azuma, K., Johnsen, S. J., Kawamura, K., Kipfstuhl, S., Kohno, M., Parrenin, F., Popp, T., Rasmussen, S. O., Schwander, J., Seierstad, I., Severi, M., Steffensen, J. P., Udisti, R., Uemura, R., Vallelonga, P., Vinther, B. M., Wegner, A., Wilhelms, F., and Winstrup, M.: Direct linking of Greenland and Antarctic ice cores at the Toba eruption (74 ka BP), Clim. Past, 9, 749-766, doi:10.5194/cp-9-749-2013, 2013. 